\title{
Dystocia Due to Monocephalus Diprosopus Monster Calf in a Non- descriptive Crossbred Cattle- A Case Report
}

\author{
K. Pratheepa", C. Arunkumar and K. Vijay \\ Department of Animal Husbandry, Tenkasi Division, Tenkasi District, Tamilnadu, India \\ *Corresponding author
}

\section{A B S T R A C T}

\section{Keywords \\ Congenital \\ anomaly, Dystocia, \\ Monocephalus \\ diprosopus, Fetal \\ monster \\ Article Info \\ Accepted: \\ 20 December 2020 \\ Available Online: \\ 10 January 2021}

A diprosopus monster fetus was delivered pervaginumin pluriparus nondescriptive crossbred cattle, which was presented with persistent straining and dystocia. The fully developed dead female fetus consisted of four eyes (tetraophthalmus), two pairs of nostrils, two mouths, each with a tongue and two ears. The neck, thorax, abdomen and limbs were grossly normal. Manual removal of diprosopus fetus was done successfully per-vaginally through dilated birth canal.

\section{Introduction}

Dystocia is the condition in which the first or second stage of parturition is prolonged, making the delivery difficult or impossible and obviously need an external aid in resolving the condition. Fetal anomalies and monsters are common causes of dystocia in bovines (Shukla et al., 2007). A monster is an abnormally formed fetus with a congenital anomaly. Conjoined twin monsters is a rare disorder occurring in monozygotic twin pregnancies (Roberts, 2004) characterized by duplication of anterior or posterior or both parts of the fetal body. But anterior duplication is more common in swine and ruminants (Arthur et al., 2001) with varying degrees of duplication and fusion. Anterior duplication of the head may be either monocephalus ordicephalus. Diprosopus is an extremely rare form of symmetric conjoined twins consisting of a single neck and body with various forms of duplication of the craniofacial structure. Monocephalus Diprosopus monsters have a single head with two faces. (Roberts, 2004).Mostly such type of monsters causes dystocia.

\section{Case history and examination}

A 4-year old non-descript cattle, with normal gestation length and in its second parity with 
the history of water bag rupture and prolonged straining for more than 8 hours without any progression was referred and was attended at the farmer's doorstep. Per vaginal examination revealed a fully dilated cervix and an abnormal dead calf with two faces joined together in anterior-longitudinal presentation, dorso-sacral position and both forelimbs flexed in the birth canal at the pelvic brim.

\section{Obstetrical management and treatment}

The cow was pre-medicated with chlorpheniramine maleate $(10 \mathrm{~mL}$, intramuscular) and the epidural block was performed by locating the sacrococcygeal space with the tip of a finger while moving the tail up and down in a pump-like manner with the other hand.

The $18 \mathrm{G}$ hypodermic needle was introduced at an angle of $45^{\circ}$ to the depth of about $1 / 2$ to 1 inch to enter the vertebral canal and $5 \mathrm{~mL}$ of $2 \%$ lignocaine Hydrochloride was administered.

Since the birth canal was dry, the vaginal passage and fetus was lubricated with the available castor oil. A long William's obstetrical hook was applied in the right inner canthus and snare was applied on both the forelimbs and two men traction was applied. Both the heads were brought outside the vulva and the forelimbs were extended towards the vulva, by traction on the fetal head and forelimbs simultaneously a forward and downward direction, the fully developed dead female monster fetus was delivered with a shiny hair coat and a single tail. The placenta was removed easily at that time. The cow was treated with inj.Ceftiofur sodium $\left(\mathrm{xceft}^{\mathrm{TM}}, 1 \mathrm{~g}\right.$, intramuscular) and inj. Meloxicam (Melonex ${ }^{\circledR}, 15 \mathrm{~mL}$, intramuscular) for 3 days. The fluid therapy was done with inj. Ringer's Lactate (2 litres), inj. Normal Saline (2 litres) by intravenous route along with supportive therapy for 3 days.

\section{Results and Discussion}

The physical examination of the retrieved dead fetus revealed duplicated facial structures (Diprosopus) on one neck (monauchenos). The calf had four eyes (tetraophthalmus), two pairs of nostrils and two mouths, each with a tongue but only two ears. No ears were present on the medial side of diprosopus (Fig. $1 \& 2$ ).

Fig.1 Diprosopusfetus head

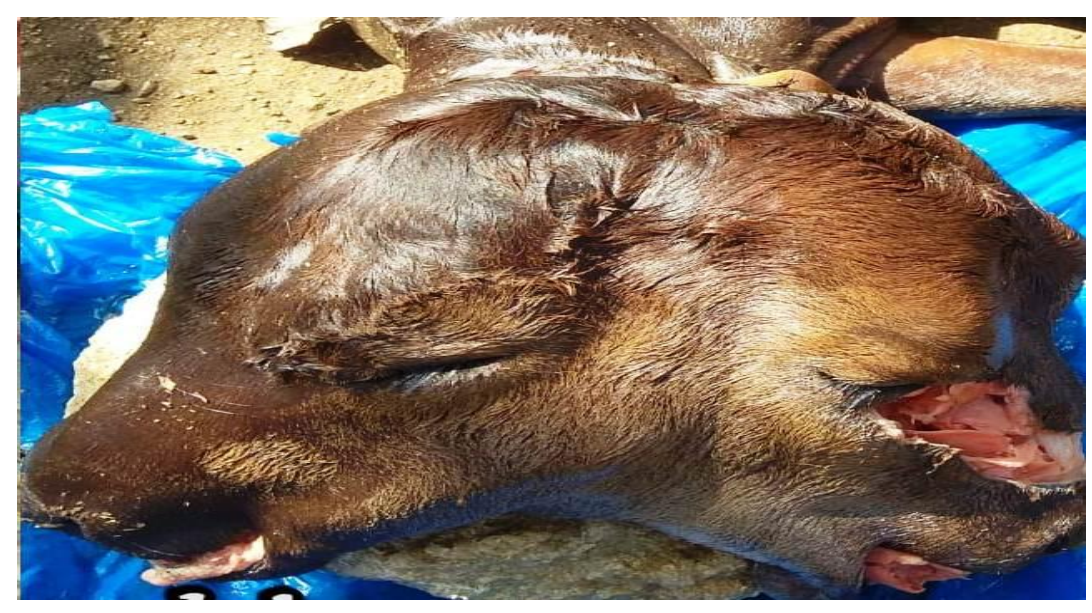


Fig.2 Diprosopusfetus

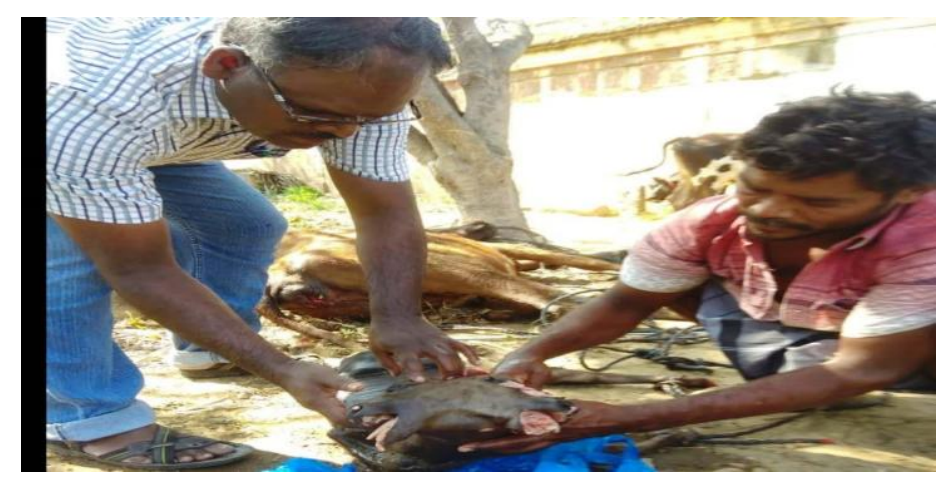

Diprosopusis usually presented with unaffected or normal internal organs. In this case also neck, thorax, abdomen and limbs were normal. These observations align with the earlier findings of Amitsharma et al., 2010, Pravesh Kumar et al., 2016, Salmai et al., 2016 and Sumena and Lucy, 2016. The pathogenesis of diprosopus may be due to the incomplete division of the zygote at a considerably late stage of embryonic development (Noden and De Lahunta, 1985) and also involves duplication of the notochord (Wu et al., 2002).

\section{References}

Amit Sharma, Subhash Sharma and Vasishta NK.A Diprosopus Buffalo Neonate: A case report: A case report. 2010. Buffalo Bulletin, 29 (1): 72-74.

Arthur GH, Noakes DE, Parkinson TJ and England GCW. 2001. Veterinary reproduction and obstetrics, 8th ed. WB Saunders Company, London.

Noden DM and De Lahunta A. 1985. The embryology of domestic animals: developmental mechanisms and malformations. Williams and Wilkins, Baltimore, pp.109-152.

Pravesh Kumar, Amit Sharma, Madhumeet Singh and Akshay Sharma. 2016. A rare case of dystocia due to MonocephalusDiprosopus Monster in a cow. Himachal Journal of Agricultural Research, 42(2):195-196.

Roberts SJ. 2004. Veterinary obstetrics and genital diseases. Indian reprints 2004, CBS Publishers and distributors, New Delhi, India. pp. 73-74.

Salami OS, Okaiyeto SO, Danbirni S, Ibe C, Allam L and Kudi AC. 2016. A case of diprosopusmonauchenos in a day old calf (White Fulani $\times$ Friesian cross) in an integrated dairy farm.African Journal of Dairy Farming and Milk Production, 3 (7): 1-4.

Shukla SP, Garg UK, Pandey A, Dwivedi DP and Nema SP. 2007. Conjoined twin monster in a buffalo.Indian Vet.J.,84: 630-631.

Sumena KB and Lucy KM. 2016. Diprosopus condition in a newborn calf. 2016. Indian J. Anim. Res.,50:275-277.

Wu J, Staffenberg DA, Mulliken JB and Shanske AL. 2002. Diprosopus: A unique case and review of the literature. Teratology,66: 282-287.

\section{How to cite this article:}

Pratheepa, K., C. Arunkumar and Vijay, K. 2021. Dystocia Due to Monocephalus Diprosopus Monster Calf in a Non-descriptive Crossbred Cattle- A Case Report. Int.J.Curr.Microbiol.App.Sci. 10(01): 3510-3512. doi: https://doi.org/10.20546/ijcmas.2021.1001.414 